\title{
Standardizing Green Space Capitation of Kerman City, Emphasizing on the Environment and Sustainable Development
}

\author{
Mohsen Ilaghi Hosseini1 * \\ ${ }^{1}$ M.A Student in Urban Planning, Kerman Branch, Islamic Azad University, Kerman, Iran \\ *The corresponding author: E-mail: Mohsen.elaghi@gmail.com \\ Ehsan Anjomshoa²
}

2M.A Student in Urban Design Kerman Branch, Islamic Azad University, Kerman, Iran

Ali Asghar Abdollahi ${ }^{3}$

${ }^{3}$ Department of Geography, Faculty of literature, ShahidBahonar University of Kerman, Iran

Doi:10.5901/mjss.2015.v6n5s2p654

\section{Abstract}

\begin{abstract}
Each activity in a city has a specific function, which is also called the activation threshold. It features the appropriate level of the fabric of a city devoted to that activity. Since this feature is based on the characteristics of the economic, social, cultural and natural characteristics of the study area varies from city to city, so realistic plans to deal it is necessary to identify and match. Urban green space from the perspective of urbanfunctions, which includes part of the city landscape is made up of a variety of vegetation and live as a critical factor in determining life in the body morphological construction of the city. Landscape in the modulation of water and air and improving the city's ecology plays significant role and causes reduction in temperature and increasing of rainfall. In Kerman region due to soil type, High temperature, low rainfall and monsoon winds, green space got somehow naked faces. On the other hand, the daily increase in population and expanding urbanization, increases air pollution and this substance increment causes harm to humans and animals. This study aimed to determine the minimum standard need of green space's capitation in Kerman city using Kambiz Bahram Soltani method. Using different indicators of climate - defined social minimum per capita that it can progress planners and city managers to execution of plans and make themto understand the current status of this use. The results show that the current capitation of green space in Kerman is 10.5 square meters which standard amount, obtained in this study, Is 49 square meters.
\end{abstract}

Keywords: standard, per capita green space, impact indicators, Kerman

\section{Introduction}

The role and importance of green open spaces in the complex biological environment and quality of life dramatically on the rise in many countries, green open spaces are an integral part of land use planning decisions (2004 chiesura,). The last member of the limited scope and function of the city and residents easy access to natural areas, mostly for specific social groups such as the gentry in terms of hunting and recreation, viewing, and so it was important to create a vision, but Today, its development due to the increasing population, rapid physical growth, development, manufacturing activity, an increase in motor vehicles, and consequently the growth of environmental pollution and the incidence of mental illness as a biological and social necessity, inevitability is. In the past decade, Kerman metropolitan rapid movement, the traditional trend toward the industrialization goes out and, in the meantime, what is very disturbing, increased toxic pollutants in the air more than 700 thousand it breathe; in the factories and industrial centers near residential areas within the city, the traffic cars are increasing in number day by day, it fueled the concerns. In these circumstances, to acknowledge everyone, what can stop this trend continues, the presence of trees and developing green spaces, in the desert town of Kerman that its climate is hot and dry, less than 15 years suffered drought. Accordingly, this issue serious attention to urban management, but the result of all activities that has been done in this regard for many years, the unbalanced distribution and very low per capita green space in the city. 


\section{Statement of Problem}

Space green to title one from the ingredients life and stability city at form attention to standards environment and distributionsuitable it at relationship with factors different since population density and area, consequently, more positive on recovery quality life andexhilaration people will found.however, at condition currently, most from towns small and great Iran with dilemma shortage space green and distribution inappropriate and lack distribution correct it faced and are that the status dissatisfaction and fall gradually quality life andealth individuals to followers will found. Aftermath development urban and complexity by issues life environmental modern that many from communities urban to involved and, existence space green and spread it to more from every time other necessary made (seemosesKazemi, Ali Akbari,2010:136). the other at world modern especially at macro city and, accumulation more from ago population restriction fcilities social and etc. effects undesirability at life and life social cultural and welfare citizenry leaves that with developmentspaces green transformation by this factors inappropriate denial never to (The wisdom, 2007: 10). in several decades recent user space green urban like other user and at lever by executive program customizable urban iethe plan comprehensive and yilispitp. case attention beenand at this plan and then from aseries studies early at case status ago and available user space green at background protection andmaintenance space green present and guessthegrowth and location access it to next politics to adoption returns is but to because out break a series issues such as the incresase severe population city spread without top cities, increase price ground by urban and etc. topower witness from between going spaces green inside and environs and more and from sincethat spaces green, lung by respiratorytowns to you to come, need renewal view at case politics by protection and maintenance and creation space green at plan by urbandevelopment necessary to view to appears. what is certain is that the standard per capita green cities, especially Tehran was not clear and it does not use planners understand the need for this. user per user particular recognition and green space managers in each region will have the opportunity to plan according to the needs of the region are targeted.

\section{Study Area}

Kerman, the provincial capital of between 56 degrees and 58 minutes to 57 degrees and 09 minutes east longitude and 30 degrees 14 minutes north latitude and 30 degrees 19 minutes, at an altitude of 1755 meters above sea level is located. The area of this city is about 14,000 hectares and a distance of $1060 \mathrm{~km}$ South East of Tehran is in a foothill location. According to the latest census the population of the city suburbs and housing more than 700 thousand people. In 1390 arena By Wild At City Kerman 2764377 Square meters, Park And spaces Green (squares, boulevards and Rfyvzh, Lchky, etc.) 4291, 480 square meters Is And A total of 7,055,857 square meters.

\section{Research Purposes}

Many commentators believe that social issues are important in reaching stable development and many government officials try to pay attention to this area. Welfare in life is divided into two dimensions: material welfare and spiritual or the very mental welfare. Spiritual comfort is more important than other factors. One of the external factors for satisfaction of welfare in crowded urban areas is urban greenery and many studies have proved the influence of green areas in citizens' comfort. Therefore, the sensitive role of urban design and planning is highly emphasized in order to keep relationship between urban areas and greenery or nature. Considering the important functions of urban greenery and its role in stable urban development, we find that creation of favorable greenery is a solution for many severe urban problems which is effective in aesthetical aspects and promotion of city appearance quality. It can prevent from economic and physical destruction of city, life quality decrease and air pollution and migration of average class from city center and it can bring liveliness to central urban areas and its surroundings and encourage people to participate.

Therefore, research goals are:

- Evaluation of green space in the city of Kerman

- Impact of changes in the standard status indicators and per capita green space, according to regional conditions

- Specify the required standard of green space for every citizen in Kerman

\section{Method}

For the purpose of this research is applied and the descriptive nature Analysis and to provide a standard figure of a little 
green space (KambizBahramSoltani) use. The data required by the study, according to documents obtained library and database Statistical Center of Iran.

To this end, qualitative methods are useful in specification of standards and all geographical areas because every region has its special climatological and topographic and ... features and it is better to use the aforementioned method and because the region under study is situated in Iranian dry belt (central plateau), KambizBahramSoltani method is more useful than other methods.

\section{Literature}

Planned open space and green background is not very long. Since the eighteenth century, the physical growth of cities was limited, so open spaces and agricultural areas adjacent to the local population as a source of food supplies to the city were to contribute. In addition, due to technical constraints and transportation infrastructure and facilities, open spaces of urban residents were most easily available; however, green area designed primarily to campus and also in the creation of landscapes and viewing the monuments government social and gentlemen, was limited.By planting trees, the hidden spaces of the poor, to beautify the urban environment can help. This situation changed following the Industrial Revolution. The creation of new income Mtab often independent of the land and technological innovation, and reduce dependence on agriculture, migration from rural areas to urban areas accelerated pace. With the expansion of urban green open spaces surrounding the dense narrow and crowded into cities, while cities were separated gradually with the growth of both spontaneous activities and spaces, wrapping plants - produced in the heart of residential centers, the creation of green space ring the old center of the city, or work centers, lack of recreation and tourism, Nabsmany health, destruction of pristine natural areas, the destruction of agricultural land, of environmental pollution, growing marginalization and even slums, they (Muhammad of data, 2005).

The vertical growth of urban space and common construction standards high, Btvrlmy into science and urban development have evolved with the development of this process in the United States of America. In 1963, the National Housing density and land use standards, the announcement of the widely used for urban development (planning office of the Ministry of Development, 2002: 111). In America, the practice of too little influence on urban development, the use of civil standards, and has been used extensively by the national and state standards and standards organizations for many different applications developed in on urban planning measures and land use studies placed. Kevin Lynch in environmental planning (Site planning) is a set of standards to calculate and proposed urban America. The book was translated and published in Persian by the standards of some of the city (the Office of Urban Planning, 1996).

Article 29 of the Charter of Athens as the Ykhvanym "tall buildings, each with a different distance to accept the will of land for large spaces and green Ybayst release. Ybayst elevated buildings to be built far from each other, or Instead of building height is only exacerbating the situation is improving there will help. "Article 28 of the Charter of the Ynvysd: "... Choosing a pleasant view, search for better weather and full sun and in the end to the creation of public social services near homes in the real life goals Ysaznd continue to house the that buildings depicture relatively elevated response should be allowed to use them properly. "

Parallel to the efforts of modern city, naturalists also seeking environmental problems attached great importance to the development of green open spaces are upgraded. They consequently inspiration of the Chicago School, which was basically in conflict with the proposed low density and especially trying to develop green spaces in the city and the region Ybashnd. Le Uninstall Frank Wright to return to nature and avoid alienation, human freedom in dwellings of the Ybynd in addition to green spaces around, have at least two hectares (Habibi, 1990). Ebenezer Howard from the point of view of thought between urban culture-oriented, nature-oriented and innovative was the first to broach the idea of blending in with the countryside, the green space in cities is emphasized. He described the interaction between urban and rural areas Ynvysd: first and foremost, the city should be green space in the city is at least 5 times. It is a garden city, Howard said a total view for every 1,000 residents, 9 acres of green space for the various amounts of lead, which is about 1 acre for every 20 houses (Avstrvfsky, 1992: 1-30)

Abrvkrmby In this regard, the Ynvysd: green open spaces in recreation and tourism, an important factor in the survival and improve the health of individuals are upgraded. Peer review, the open spaces of the UK, representing a difference of $43 / 2$ hectares (6 square meters in 4047 if equivalent) in wool s to 04/0 acres (1.0 lker) for 1000 in Shvrdych Undergone. Abrvkrmby considering the amplitude (about 60 times), the conclusion of outdoor Yrsd standard offer. He is the $62 / 1$ acres (4 lker) in 1000 to justify the figure indicates YdardYdand and that this figure is significantly lower than the 83.2-hectare (7 lker) by many authorities in England and even other countries in the world have been proposed. But in areas where land use is compressed, the greater the exposure can Ypzyrd (Turner, 1992)

Some of the standard urban green space ideal amount to one tenth of the total surface area of a nineteenth 
Ynmaynd the proposal, while the maximum walking distance to the farthest residential access to green spaces should not exceed ten minutes. Shhrsazany like Wolf The average size of 5.3 square meters for each citizen to have known that the amount of square meters of parks and gardens in the neighborhoods 75/2 does the Yyabd. Some parks outside the city and inside the city 30 square meters per capita are considered and undertaken (Afshar, 1995).

According to studies conducted in the world in terms of distribution of urban green space, urban green open space per capita standard of 15 to 50 square meters per person is considered (Bijan-Zadeh, 1990). Standards of green space in the United States, 50 in Germany, 30 to 60,50 to 60 in Switzerland, Sweden, 50 to 60 square meters per citizen (Management and Planning Organization, 2001); however, in Los Angeles, 154 square meters, Boston 117 square meters, 47 square meters in New York, San Francisco, excluding parks outside the town of 11 square meters for each resident of the 9 and in London, Paris and Bonn 7.5 4.7 square meters of green space per resident of the include (Afshar, 1995). $73 / 4$ square meters of green space per capita share in Japan and in the cities of Moscow 45 and Kiev 25 square meters (Mjnvnyan, 1995) While the green open spaces of Tokyo in earthquake zone as a function of development strategy However in 1994 they view the standard green open space per person Baza' due to population density and limited land, about 42/5 square meters was determined (Song and Nishimura, 2005)

Butler per 1000 population, 10 lker parks and green spaces in the city, and the same amount on other forms of green space outside the city knows enough of it. Butler offers will not stop here. He suggested that the projects of housing and residential areas that do not match the size of 465,279 square meters of land to develop their game. They play land with a range of $1 / 474 \mathrm{lker}$ need between half a mile (equivalent $1609 \mathrm{~m}$ ) is made of children's lives. Every 800 people must have the equivalent of $1 \mathrm{lker}$ green space. Iker is a large park area should not be less than 100. Every city should have at least a large park. 40 thousand people in the big cities should (D) enjoy a large park. In addition to the big city to store natural supports outside the city is an area of at least 1,000 lker (Mjnvnyan, 1995: 54).

Park neighborhood standard in the United States, Baza' per 1000 population $1 / 4$ to $1 / 2$ mile radius around 4 Iker performance standards Baza' park area per 1,000 inhabitants with a radius of 5.1 miles to the first of the 7 is Iker. To put it more clearly in scale neighborhood parks per capita standard of 16 square meters and 28 square meters in area scale (Charles and Nicholas, 1988).

Some planners, high standard of green space per thousand residents 10 IkerBaza' the complex life of their proposal (Mertes and Hall, 1995) Bear and Higgins (1381) of the new document: "Studies of the use of open spaces and recreation areas suggests that the majority of people prefer to have a long walk to the use of green space. " $400 \mathrm{~m} 10$ minutes walk as is common for those who are regularly going to use this space. That is why the planner to study local green spaces within 400 meters of the project limit. Studies have shown that the use of open space land only if they are certain to have a longer distance people are willing to take it over It should be noted that the issue of space, standard vertical growth of cities and the spread of high-rise construction, have more contact with their development, has evolved. For example, in 1963 in the United States by the National Housing Authority, "the density standard 9 "was announced, which was used extensively in the city. In America the practice too little planning methods, the use of multiple users of different standards and regulations developed in urban planning studies and calculations on the land of the served.

Makhdoom (1990, p. 58) standards with respect to different ecological conditions, especially climatic conditions between 50 5/7 square meters with a relatively high level assessment of the proposed AD. The report studies country's urban planning department, the quote that normal life is possible where the share of green space per person in a residential area not less than 30 to 50 meters and to park more than a quarter not hours. It should be noted that Iran has normally planned green open spaces in the neighborhood or urban scale without adjustment and implementation of the necessary standards of other countries and, in some cases without any pattern of the standards a other urban designs used (meeting, 1994). However, the reported contract of comprehensive urban plans of housing and urban development department's standard minimum of 6 and a maximum of 20 square meters of green space per person is accepted with a mixture of one-third of parks and gardens and two-thirds of the fields is sports, and games . It should be noted that currently accepted standard of comprehensive plans for approval in relation to the per capita green space in cities between 7 to 12 square meters (Department of Urban Planning, 1990: 17). However, a check of the action showed that the vast amount of green space in cities, compared with the proposed significant difference and is necessary for its development by planners and administrators of more done. It should be added at the end of this section discusses the criteria and standards of green space in rural areas of the country. 2 square meters per capita average in the debate, as has been proposed for rural areas (Secretariat of the Supreme Council of Planning and Architecture, 1999).

In the 1960s and 1970s by various entities affiliated with the United Nations standards of life and environment, justice and social welfare services and other development goals in different countries developed and their use is recommended. These standards as a tool in planning economic development - Community countries, such as urban 
planning is used (the Department of Housing and Urban Development, 1992: 107)

In Iran, directly or indirectly urban standards, including standards for space, broad use planning, including urban design has (Hosseini, 1992). Mohammad Taghi Razavi book analyzes urban land use planning and urban land use standards on the part of the book examines the standards of urban green space. In this book, to access the city's population as the two factors mentioned in the planning of green space (Razavi, urban land use planning: 135).

\section{Definitions and Concepts}

\subsection{Urban green space}

Fresh green word phrase that just less than half a century for urban planning used in the literature (Consulting Engineers attack, 1: 1989) between green space and green area of ecological differences and the differentiation of these aspects is important green areas green space like the Forest Act of dust cannot carry out have an effective role or reducing noise or in an appropriate manner to reduce the temperature (Saeed Nia, 29: 2000).

There are several types of green spaces such as gardens, agricultural land, green belts, Green spaces barrier, green strips along roads, Public buildings and green homes and green space parks etc. (Saeed Nia, 39: 2000). Urban green space of urban open space and natural areas that cover most artificial trees, Buds, Plants, flowers, Grass and other plants under the supervision and management of people with regard to the terms and conditions related to the improvement of living conditions and welfare of citizens and non-rural population centers, constructed and maintained (Management and Planning Organization, 24: 2001). From urban planning viewpoint, urban green space includes some part of city's face which is combined from different types of plants and as a living and crucial factor in addition to the city's lifeless physical frame, it determines morphological structure of the city.

\subsection{Types of Urban green space}

In general it can be said that the urban landscape is divided into four major categories are divided as follows: public green spaces, semi-public, and private green and street green.

\subsection{Developing sustainable relationship with the environment is the following}

Sustainable development and its relationship with environmental NGOs in the world of contemporary critical moments of its life. Still there is much inequalities left in human society. Poverty, hunger, lack of education and health, and legitimate freedoms in all countries, at different scales, phenomena are known and concrete. Unreasonable increase in population along with the above factors, environmental Bvmhayy which human life depends, have greatly endangered. However, to avoid utter destruction of the environment, all people in human beings, both decision-makers and others in the international dimension. The development of contemporary people should not be overwhelmed at the expense of future life for the protection of their rights are not present, all. We must also learn to develop the right of all people, including men, women, and children, young and old, not only should all benefit from the fruits of which should also participate in the development process. A country whose people are aware of environmental issues than other developing countries, is fortunate.Environment such as forest loss, desertification, soil erosion, water pollution, air pollution, extinction of biodiversity problems related to solid waste and wastewater and others to create their own determination as to stand up and rehabilitate national consciousness try to complete the problems. The concept of sustainable development was raised when environmental issues were at the forefront of political debate and thereby work instead, the concept of the impact of environmental changes act as an instrument for the protection of the environment has been prepared. Thus, in 1992 the Conference on Environment and Development, entitled "Earth Summit" in Rio de Janeiro in Brazil and with the participation of delegations of 180 countries was formed.

\section{The Findings}

\subsection{Check the status of green space in Kerman}

Green space environment of the United Nations, as well as an indicator to assess the purpose of the application development itself has. However, this figure in Iran, according to studies by the department of housing and urban development, from 7 to 12 square meters per person intended as compared to the world, far seen be. At Kerman 
according to the area and density of population and area Space there are herbs that this figure is much lower than the standard. Capitation of that to be with attention to condition climate and environmental quality Kerman is much more than the status quo. with the calculation that uses the global positioning system is done, the area of space green city Kerman more than 700 hectares is almost 280 acres from this level to forest park vertical and martyr bahonar formation the and the rest it spaces green inside city is. however, in however, present level percapita Space Green City Kerman with including parks vertical and martyr Bahonar,5.10 $\mathrm{m}$ is, that this level without at view catch the park, about $7 \mathrm{M}$, which is much lower than the international standards and Iran.dtandard defined the world for per capita green area of about 25-20 and standard state 12-7 $\mathrm{m}$ square to every person is and with attention to matter that space green at improvement of living to per room green at kerman more down and is.

\subsection{Calculation of urban green space}

Here, according to a study of urban green space per capita Mr. KambizBahramSoltani calculation method is presented. The concept of green space can only be used in urban green spaces for leisure, play and recreation were provided. Otherwise, words cannot arbitrarily be logical sense.To calculate the per capita green space can be several factors to be considered. On this basis the number of parameters involved in the calculation of the per capita increase as well as the results will be more accurate and the psychological and social needs of the urban population feet of street will be more appropriate. However, the use of multiple parameters requires that each data exist. The use of a large number of parameters can reduce the risk of operational value calculation method is also considered. Considering the above, the method for calculating green space within urban cities below is recommended. This model has been used in the design of four parameters: (Ziyari, 2009: 298)

1. The average area needed for healthy growth of a tree

2. Features Local Climate

3. Environmental Quality

4. Density people / room residential units.

The average area needed for healthy growth of a tree to calculate the area of a circle with a radius of 5.1 meters, which is located in the center of the tree, is obtained. This area of 7 square meters. The soil should be level with any construction (asphalt, pavement, cement, etc.) remain free of any disturbance in this way prevent root activity.

To determine the characteristics of the climate where the average maximum temperature in the hottest month of the year the design of the appropriate criteria to determine the severity of the heat in summer is used.

Table 1: Classification of average maximum temperatures during the hottest month of the year and the coefficients range of green space

\begin{tabular}{|c|c|l|}
\hline During the heat $\mathbf{F}$ & Coefficient of $\mathbf{b}$ SpaceGreen & Explanation of pages \\
\hline 25 & 1 & Cease to workSuitable \\
\hline $30-25$ & 2 & Suitable \\
\hline $35-30$ & 3 & Able Agree \\
\hline $40-35$ & 4 & Inappropriate \\
\hline+40 & 5 & Enough of the bad \\
\hline
\end{tabular}

Source: (Ziyari, 2009, p. 300)

Table 2: Quality of the environment and green spaces coefficients

\begin{tabular}{|l|c|l|}
\hline Description & Ratio of green space & Environmental quality \\
\hline There is no air pollution and noise. & 0 & Very good \\
\hline Air pollution in some time, andpollution There is some noise during the day. & 1 & Suitable \\
\hline Noise pollution or air in the hours of the day there. & 2 & Inappropriate \\
\hline Both types of contamination during the day There. & 3 & Very poor \\
\hline
\end{tabular}

( Source Ziyari, 2009, p. 300) 
Finally, the number of people living in residential rooms for social factors arbitrarily used. Table 3 to provide needed social factors in the per capita green area is provided. The table measures favorable conditions is that each of the residents of a residential unit, a room of their own. On this basis the number of people living in one room to grow as well as residential space will degrade the quality of life and the need for green space in the non-residential space is increasing.

Table 3: Compression ratio $\mathrm{n} /$ garden room and coefficients

\begin{tabular}{|l|c|l|}
\hline Description & Coefficients green space & Density people / room \\
\hline Very good & 0 & 1 person / room \\
\hline Tolerable & 1 & 2 persons / room \\
\hline Very poor & 2 & 3 person / room \\
\hline
\end{tabular}

( Source Ziyari, 2009, p. 300)

With Attention To Index By Definition From Above To Purpose Calculation Capitation Space Green City Kerman This Wa y Action To Be.

Standard green space Qt max + Qeq + Qp / R)

Qt max = constant area for the growth of a tree $(7 \mathrm{~m})$

Qt max = green climate index

Qeq = Rate the quality of the environment and green spaces

$\mathrm{Qp} / \mathrm{r}=$ Index of / green room

After the standard in order to calculate per capita green space with all three factors together, compared to 7 meters multiplied.

To calculate the per capita green area of the city of Kerman is done this way:

1. To To the features By Climate location Case Designing from Factor Average Max. The temperature of the air At Warmest Month Year ThatNormative Suitable to Diagnosis The severity of hot air At Season Summer Is Use from Is. In Kerman, the hottest month of the year is July, with an average of 2/39. According to the table of coefficients due to the temperature range for the poor is a factor of 4 .

Table 4: The temperature of the air in Kerman at Warmest Month Year

\begin{tabular}{|c|c|c|c|c|c|c|c|c|c|c|c|l|}
\hline March & To me & D & December & November & Seal & September & August & Bar & June & May & April & Temperatures month \\
\hline 28 & 19 & 21 & 22 & 26.4 & 33 & $37 / 8$ & $38 / 2$ & $39 / 2$ & $38 / 4$ & $35 / 4$ & 6.27 & Maximum Absolute \\
\hline
\end{tabular}

Kerman Meteorological Organization, 1390

Table 5: Zry of green space in the thermal range Kerman

\begin{tabular}{|l|l|l|l|}
\hline Inappropriate & 4 & 40. & -35 \\
\hline
\end{tabular}

2. To engage the features and sound quality of ambient air pollution in the calculation of the parameters used. Because of Kerman in some hours of the day faced with noise pollution or air quality of the environment in the table (Table 2), in a difficult situation and it is a factor of 2.

Table 6: Ratio of green space in Kerman quality of the environment based on information from the organization Environment Life Province Kerman

\begin{tabular}{|l|l|l|}
\hline Noise pollution or air in the hours of the day There. & 2 Inappropriate \\
\hline
\end{tabular}


Table 7: Coefficient of compression ratio of green space / room, according to data from the Housing and Urban Development Kerman province

\begin{tabular}{|l|l|l|}
\hline Tolerable & 1 & 2 persons / room \\
\hline
\end{tabular}

The coefficients applied to the minimum standard indicators capita green space in the city of Kerman through the following equation is:

\section{Conclusions}

The environment and green spaces have a big impact on the lives of city dwellers and can strongly influence the sustainable development of cities to accelerate. Square meters per person. (Housing and Urban Development). Of course in different cities of the country, per capita, according to the different geographical and climatic characteristics are different and each of the cities to determine approved projects. The standard per capita by in this study is 49 square meters with the status quo far. Imbalance in the distribution of green space in the city as one of the problems of green space Kerman. However, the management and the importance of trying to preserve green space, an important component of Kerman and other cities who can enjoy this gift from God. The culture of the people is an important factor in maintaining and even increasing green spaces.

\section{Rather Specific Suggestions}

10.1 General

1. Providing services to the private sector for the development of green spaces

2. Modify spaces incompatible with the development environment

3. Strengthening urban management

4. Culture for the preservation of green spaces

5. Planting and maintenance of trees and plants to encourage public

6. Providing information to the public about the need to preserve green spaces

7. Development of urban green spaces without harming other plant species

8. Creating green spaces to achieve sustainable development

9. Use plant diversity to suit the climate for creating urban green spaces

\subsection{Regional (Kerman)}

10. Development of Forest vertical and martyr Bahonar with management and consider all aspects of the

11. Kerman increase green spaces in all their proportional distribution

12. The lack of green spaces on the surface, such as grass and tall trees growing attention

13. The distribution of green space in a way that will benefit all regions

14. According to the sustainable development and towards achieving these important

15. The use of technology and technology to promote the creation of green spaces.

\section{References}

Afshar, a. (1995), urban master plans, Tabriz, Tabriz University.

Avstrvfsky, and. (1992), urban contemporary, translation Laden Etezadi, Tehran University Publishing Centre.

BahramSoltani, one. (1992), discussion of methods Urban Development, Urban Development and Architecture Research Center, Tehran.

Bijan-Zadeh, M. (1990), studies of green spaces in Tehran, Tehran: Publication of the cultural department of the University Jihad headquarters.

Charles W. Nicholas H \& TD (the 1988th), "Tine-Standards for Landscape Architecture Design and Construction Data ", New York: McGraw-Hill Book Co.

Chiesura, A, (2004), "The role of urban parks for the sustainable city", Landsc. Urban Plan. 68 (I), pp. 129-138.

Engineering consulting the attack. (1989), studies of the ENVIRONMENTAL Tehran.

Frankenberg et al, E. Frankenberg, "E. Sadot, R. Ortal and U. Safriel, (1991), Guidelines for Ranking the Nature Value of Open Specs", 
Nature Reserves Authority.

K. De Ridder, (2004), an integrated methodology to assess the benefits of urban green space, science of the total environment.

Marcus CC and Francis C (1990), "People Place: Design Guideline Urban Open Space", Department of Architecture and Landscape Architecture, University of California, Brekeley.

Maruani. (2007), "Open space planning models: A review of approaches and methods ", Landscape and Urban Planning, Volume 81, Issues 1.2, 29, Pages 1-13.

Mertes. D, and R. Hall (1995), "Park, Recreation, Open Space and Greenway Guidelines", Alexandria, VA: National Recreation and Park Association.

MousaKazemi, Q of the M \& Ali Akbari, Q. (2010), and analysis of the social set up of the following you should talk to the slide with thedistribution of green space use.

Office of the Ministry of Construction Zi. (2001), per capita user of utilities, Volume I, published by the mayor of the country.

Par stoic in Z, N. (2005) analyzed the spatial distribution and location of Kerman green space, conference development, architecture and urban planning.

P. Pregill and N. Volkman. (1993), "Landscapes in History: Design and Planning in the Western Tradition", Van Nostrand Reinhold. New York.

Pour-Mohammadi, M. (2003), the program of urban land use Zi, the publisher, Tehran.

Razavi, d. (2002), the program of urban land use Zi, Tehran, and Press Secretary.

Sense of straw, AS. (1992), minimum standards of per capita land use in urban plan, Plan and Budget Organization of Fars province.

Song. And Nishimura. (2005), "Urban Open-Space for a Sustainable City: Application to the Tokyo Area", Department of Urban Engineering Graduate School of Engineering, University of Tokyo.

Try to be or not, A. (2000), urban green spaces, urban Zi Press Center of the Ministry of Interior of the program.

Turner, T. (1992), "Open space planning in London: From standards per 1000 to green strategy", Town Plan. Rev. 63 (4), pp. 365-386.

Wisdom, c. (2007), horticulture, publishing sphere. 